\title{
O ensino de Medicina Legal em São Paulo
}

\begin{abstract}
Para se avaliar como se faz, na Faculdade de Medicina de São Paulo, o curso de Medicina Legal, transcrevemos a seguir o relatorio apresentado ao director da nossa escola medica pelo cathedratico da cadeira, prof. Flaminio Favero, em 31 de dezembro de 1926.
\end{abstract}

“Exmo. Snr. Dr. Director.

D E accôrdo com o que estatúe o nosso Regimento Interno, em seu artigo 46, lettra " $r$ " cabe-me a incumbencia de apresentar a V. Ex. ${ }^{a}$ o resumo de todos os trabalhos realisados na cadeira de Medicina Legal durante o anno de 1926. Tratando-se de uma cadeira no regime do tempo integral, a minha exposição deve abranger não só o periodo lectivo propriamente dito, mas sim todo o periodo comprehendido entre $1 .^{\circ}$ de janeiro e 31 de dezembro, durante o qual a mesma funccionou, ininterruptamente, em suas multiplas actuações, dentro e fóra da faculdade.

Para methodisar a explanação abaixo, divido essas actuações da seguinte maneira:

$\mathrm{I}$ - O ensino da medicina legal;

II - As pesquisas e os trabalhos de medicina legal realisados na cadeira;

III - O exercicio da medicina legal a cargo do pessoal docente;

IV - As funcções auxiliares da administração da Faculdade a cargo do pessoal docente.

\section{I - O ENSINO DA MEdicina LEgal.}

Este ensino, durante o anno lectivo de 1916, foi feito satisfatoriamente, dentro das restrictas possibilidades das installações actuaes e dos recursos didacticos á mão, e constou da execução, em sua quasi totalidade, do programma approvado pela Congregação. A parte theorica, que comprehende a medicina legal propriamente dita e a deontologia, foi dada em 70 liçôes, durante as quaes os diversos capitulos da materia foram abordados. Esteve toda ella a cargo do professor cathedratico, excepto uma lição que foi ministra- 
da, com autorisação de V. Ex. ${ }^{\text {, }}$, pelo Dr. J. de Moraes Mello, illustre psychiatra da Penitenciaria do Estado, que tratou dos "regimes penitenciarios"

A parte pratica se processou em 45 lições, das quaes 30 de technica de laboratorio, a cargo do $1 .^{\circ}$ assistente da cadeira, sob a orientação do professor, 12 de critica e redacção de doccumentos medico-legaes e 3 de clinica forense, realisadas pelo professor. Além destas aulas theoricas e praticas, e dos varios exames theoricos e praticos especificados no Regimento, realisaram-se 3 excursões scientificas, das quaes 1 á Penitenciaria do Estado e 2 á Delegacia de Technica Policial. Infelizmente, por motivos estranhos á vontade do pessoal docente e perfeitamente conhecidos de V. Ex. ${ }^{a}$, a pratica da necroscopia forense, tambem neste anno, foi inteiramente sacrificada. Espero ardentemente que, em tempo muito proximo, quando installado em sua séde propria, o Instituto de Medicina Legal "Oscar Freire" preencherá a contento todos os fins que delle se deve exigir, sanando-se, portanto, o inconveniente apontado. A pratica de technica de laboratorio e de critica e redaç̧ão de documentos medico-legaes poude realisar-se de modo quasi perfeito, com material obtido pelo $10^{\circ}$ assistente e com casos examinados pelo pessoal docente no Forum Criminal. A pratica de clinica forense. onde apenas se simularam pericias, poude, ainda assim, ser feitả graças á extrema gentileza e bondade do Dr. J. Ayres Netto, que poz á disposição da cadeira o seu serviço clinico de cirurgia de mulheres na Santa Casa. Sou muito grato, portanto, a esse amavel collega.

E aqui, então, é opportuno o pedido vehemente que endereço a V Ex. ${ }^{a}$, para que, além da installação definitiva e completa do Instituto de Medicina Legal "Oscar Freire", cuja promessa tive a ventura de ouvir por mais de uma vez de V Ex. ${ }^{a}$, providencie tambem essa digna directoria para que o ensino da medicina legal possa ser feito, entre nós, na altura do justo conceito de cidade culta que tem a nossa capital. Para tanto, Snr. Director, é imprescindivel se estabeleça qualquer accôrdo com o Serviço Medico-Legal da Policia "desideratum" pelo qual tanto trabalhou o meu saudosissimo mestre Oscar Freire, explendido ornamento da medicina legal brasileira. Não posso comprehender o verdadeiro ensino technico da medicina legal sem tal auxilio, assim como ninguem admitte o ensino da clinica sem os recursos do hospital. Neste ultimo caso, teriamos, medicos de gabinete, que iriam aprender a examinar doentes e a fazer diagnosticos ás custas dos seus proprios clientes e, no outro caso, teriamos, ou melhor, temos fatalmente, inexoravelmente, medicos legistas que vão adestar-se nas primeiras noções de technica de clinica forense, quando tiverem de funccionar nas primeiras pericias.

Em ambos esses casos, num, por hypothese apenas, noutro, a realidade de cada dia - teremos a desastrosa acção de um profissional inteiramente inhabil no seu mister, nos primeiros tempos do seu tirocinio. 
Não seria innovação nossa esse accôrdo, porque, em nosso Paiz, da Bahia, o grande ninho de intellectuaes de cujo seio, entre outros muitos, surgiu um Oscar Freire, ha témpos vigóra, desde quando foi instituido por obra deste meu carissimo mestre, e, no estrangeiro, é exemplo communissimo.

Até na propria Allemanha, onde espiritos apressados não poderam ou não quizeram ver o auxilio da pericia ao ensino, elle existe incontestavelmente, segundo o insuspeito e recentissimo testemunho de Leonidio Ribeiro, formoso talento em medicina legal. Porque este nosso atraso, pois, no ensino technico da medicina legal?

V Ex. ${ }^{a}$ e o benemerito Governo do Estado, que tanto são credores de viva gratidão por parte da Faculdade de Medicina de S. Paulo, pela qual com carinho se interessam, V Ex. ${ }^{\mathrm{a}}$ e o benemerito Governo do Estado, digo, fariam jús ao mais sincero reconhecimento dos futuros medicos legistas e da Justiça do Estado, si tocassem a mola mysteriosa que anima a possibilidade de um ensino medicolegal efficiente e digno.

\section{II - As pesquizes E os trabalhos,de medicina legal REALisados NA CADEIRA.}

Como nos annos anteriores, tambem no de 1926 a cadeira teve o privilegio de enriquecer a litteratura medico-legal brasileira com bôa cópia de trabalhos, alguns de real valor.

Sabe V. Ex. a que, desde a sua installação, em 1918, tem sido esta cadeira procurada pelos doutorandos da nossa Faculdade e tambem de outras, afim de fazerem as respectivas theses inauguraes. Como em geral esses trabalhos são realisados sob as vistas do pessoal docente, que acompanha e fiscalisa as necessarias experiencias e pesquisas, os trabalhos emprehendidos teem um cunho de incontestavel sinceridade em suas conclusões.

Até hoje, sómente em theses de doutoramento, a cadeira de medicina legal contribuiu com um total de 64 trabalhos para a bibliographia brasileira, não muito rica aliás. Note V. Ex. ${ }^{a}$, que, dentre esses, ha alguns de real valor, como, por exemplo, o do Dr. Walt demar R. Belfort Mattos, levado a termo em 1919, sob a fiscalisação de Oscar Freire, e que versou sobre "as sarcophagas de S. Paulo" trabalho esse já em $2 .^{a}$ edição, facto ainda virgem na historia das 291 theses apresentadas, até hoje, nesta Faculdade.

São os seguintes os trabalhos publicados no anno de 1926. feitos em parte ou em sua totalidade na cadeira de medicina legal.

1) Oscar Freire - Exames e pareceres medico-legaes - Collectanea de 26 trabalhos, obra postuma do fundador desta cadeira, cuja publicação, convenientemente autorisada, acompanhei e prefaciei. Tem merecido ella os maiores elogios dos competentes na ma- 
teria, nacionaes e estrangeiros, e vultuosamente enriqueceu a litteratura medico-legal brasileira.

Convém assignalado que todos os exames e pareceres nella contidos foram feitos por Oscar Freire em S. Paulo, na regencia desta cadeira que elle tanto honrou.

2) Afranio Peixoto, Flaminio Favero e Leonidio Ribeiro Medicina legal dos accidentes do trabalho e das doenças profissionaes - E' um livrinho que tem tido já grande extracção e recebido francos elogios, e destinado a servir de guia a estudante de medicina e de direito, a peritos e magistrados, constando de tres partes distinctas: doutrina, a cargo de Afranio Peixoto, conhecido expoente da cultura scientifica e litteraria brasileira, pericia, a meu cargo, e technica, aos cuidados de Leonidio Ribeiro, docente livre de medicina legal na Faculdade de Medicinä do Rio e valoroso conhecedor da especialidade. A parte que ficou aos meus cuidados foi escripta á sombra desta cadeira, no inicio deste anno.

3) Nicoláu Sarno - Determinação da edade no vivo pela radiographia dos ossos das extremidades (contribuição) - trabalho feito no Gabinete de Radiologia da Santa Casa e nesta cadeira.

4) Francisco Alves Corrêa de Toledo - Contribuição ao estudo das tatuagens em medicina legal — trabalho feito na Penitenciaria do Estado e nesta cadeira.

5) Milton Olyntho de Arruda - Da identificação do recemnascido - trabalho feito na Clinica Obstetrica da Faculdade e nesta cadeira.

O primeiro e os tres ultimos, mórmente o ultimo, mereceram elogios do prof. Mario Carrara, de Turim, que me escreveu amavel carta largamente divulgada pela imprensa e na qual pedia a remessa de alguns clichés para publical-os, com um minucioso resumo, no seu "Archivio di Antropologia Criminale, Psichiatria e Medicina Legale" fundado por Cesar Lombroso. Adante lerá V. Ex. ${ }^{a}$ os dizeres dessa carta.

6) Terencio Milita — De uma nova technica na identificação do sangue - trabalho orginal feito nesta cadeira.

7) Aldino Schiavi - Infancia e criminalidade - trabalho feito nesta cadeira.

8) Marcello Guimarães Leite - Contribuição ao estudo das polvoras e modo de as identificar - trabalho feito nesta cadeira.

9) Attilio Oglietti - Contribuição ao estudo medico-legal das cicatrizes - trabalho feita nesta cadeira.

10) Gastão Fleury Silveira - Determinação da data do uso de uma arma de fogo e da munição - trabalho feito nesta cadeira. 
11) Almiro dos Reis - A dentada na identificação - trabalho feito nesta cadeira.

12) João Octavio Nebias - Dos estygmas profịssionaes, subsidio ao seu estudo - trabalho feito nesta cadeira.

13) Mariano Leonel Netto - Do estado anterior nos infortunios do trabalho (contribuição ao seu estudo) - trabalho feito nesta cadeira.

14) Dirceu Vieira dos Santos - O direito de curar, estudo de jurisprudencia medica - trabalho feito nesta cadeira.

Além destes, outros existem em collaboração, que não puderam ser terminados em tempo de figurar nesta lista, convindo assignalar um do Dr. Arnaldo Amado Ferreira, $10^{\circ}$ assistente, sobre a identificação das manchas de substancia nervosa, onde se trata da adaptação á medicina legal de uma technica utilissima para a identificação desse material, e cujo uso já foi introduzido no curso pratico do anno lectivo ora findo.

A respeito de varias contribuições acima enumeradas e de outras anteriores, não posso furtar-me ao desejo de transcrever duas honrosas cartas que me foram dirigidas pelo Prof. M. Carrara, de Turim, e que por si sós, quando mais não houvesse, recompensariam de sobejo os esforços dispendidos em minhas funç̧óes.

$1 .^{\mathrm{a}}$ carta - "Turim, 11 de setembro de 1826 - Illustre professor - Sómente agora, voltando a Turim, depois das férias, encontro as publicações do seu Instituto, que teve a bondade de me enviar. Agradeço-lhe muito e me congratulo com V pelo piedoso cuidado com que, honrando a memoria do seu illustre mestre Oscar Freire. salvou da dispersão e assegurou á admiração scientifica tão interessante documento da producção medico-legal brasileira. E essa que escolheu é certamente a melhor maneira de honrar os mortos: eternisar-lhes a obra scientifica!

$\mathrm{Li}$, tambem, com muito interesse, as tres memorias dos seus discipulos, que attestam a habilidade e felicidade da sua acção directora e didactica. Agradou-me muito o trabalho sobre identificação dos recem-nascidos, que é original do Dr. de Arruda; aquelle da tatuagem, do Dr. Corrêa de Toledo, é muito bem cuidado e rico de documentos photographicos preciosos; não creio, porém, como não acreditava Lombroso, que a simples "imitação" possa explicar a grande frequencia da tatuagem e os seus caracteres especificos entre os criminosos. Muito importantes, tambem, do ponto de vista medico-legal, são as radiographias do Dr. Sarno. Darei, pois, bom resumo dessas tres memorias, bem como do livro de Freire, no "Archivo" E, para favorecer a diffusão de que são dignas estas tres importantes memorias, desejo publicar, com os respectivos resumos, a reproducção das principaes e mais significativas figuras que as ornam: tanto dos pés dos recem-nascidos, como dos nucleos de ossificação, e das mais 
importantes tatuagens. Rogo-lhe, por isso, enviar-me os respectivos "clichés" Reproduzirei as figuras no "Archivo" e depois os devolverei. Assim, faremos tambem obra de uma sympathica e proficua aproximação scientifica internacional! Com os protestos da mais profunda deferencia, creia-me, illustre collega, seu (a) M. Carrara"

2. ${ }^{\text {a }}$ carta - “Turim, 3 de novembro de 1926 - Illustre professor - Recebi os dois pacotes de publicações que teve a gentileza de enviar-me. Estou verdadeiramente admirado da existencia e da importancia da producção scientifica do Instituto de Medicina Legal que V. dignamente dirige. Não li ainda todas as numerosas theses, mas vejo que algumas teem grande interesse seja doutrinario seja pratico para a nossa disciplina.

No fasciculo do meu "Archivio di Antropologia Criminale e Medicina Legale" que está para sair, disse já algumas palavras a respeito do livro do pranteado e illustre Oscar Freire, que V., por igual, gentilmente me mandou: mas em um proximo fasciculo quero tambem citar as mais importantes, pelo menos, das suas publicações. E assim pretendo contribuir tambem eu no intercambio cultural e na affirmação de colleguismo scientifico que V. assim nobremente affirmou mandando-me os preciosos fructos da actividade sua e dos seus discipulos. Creia-me, entretanto, com renovados agradecimentos e com particular deferencia, seu (a.) M. Carrara"

III - O EXercicio da medicina legal a CARGo do PESSOAl Docente.

Como era praxe desde a installação da cadeira, tambem no anno lectivo de 1926 o pessoal docente prestou os seus serviços á Justiça, em varios processos em andamento no Forum Civel e no Forum Criminal. No anno de 1926, comtudo, graças á esclarecida orientação do D. Governo do Estado e de V. Ex. ${ }^{a}$, estabelecendo o regime do tempo integral para a cadeira a meu cargo, esse auxilio á Justiça poude ser intensificado, de accôrdo com o opportuno offerecimento que V. Ex. ${ }^{a}$ houve por bem fazer ao M. Juiz Presidente do Forum Criminal, no inicio do anno ora findo, pondo á disposição da Justiça os serviços da cadeira.

Assim, o pessoal docente poude realisar: a) no Forum Criminal, 60 exames periciaes, entre exame de edade, de corpo de delicto e de sanidade physica, sendo que 15 na $1 .^{\mathrm{a}}$ vara, 4 na $2 .^{\mathrm{a}}$ vara, 15 na $3 .^{\mathrm{a}}$ vara e 26 na $4 .^{a}$ vara. Destes exames, alguns sómente poderam ser ultimados depois de pacientes e demoradas pesquisas e experiencias, o que permittirá, em futuro proximo, a publicação de interessantes trabalhos; b) no Forum Civel, um exame em melindrosa questão de annullação de casamento. Além destes trabalhos, a cadeira foi solicitada para a elaboração de 8 pareceres medico-legaes, em questões contenciosas, que demandaram cuidadoso estudo, para expedir 5 attestados de exames genitaes em pessoas do sexo feminino, para um exame de 
determinação da morte real, em que foi empregada a excellente prova da fluoresceina de Icard e para uma excursão pericial ao interior do Estado.

Não posso deixar de renovar o meu louvor ao acto de $\mathrm{V}$ Ex.a, pondo a cadeira de medicina legal á disposição da Justiça, porque, com grande satisfação, vejo que os seus serviços teem sido julgados uteis pelos M. M. e integros Juizes da nossa Capital, já não fallando no facto de sempre dahi surgirem possibilidades para os alumnos auferirem ensinamentos varios ou mesmo o esboço de theses inauguraes, como tem succedido diversas vezes. E porque não acalentar a esperança de constituir essa cooperação - ponto de partida para um futuro entendimento com a propria Policia?

\section{IV - As funcções auxillares da administração da Faculdade, a CARGO DO PESSOAL DOCENTE.}

A cadeira de medicina legal ainda poude, no anno de 1926, ser util á administração da Faculdade, em bôa hora entregue á dedicação de V. Ex. ${ }^{a}$, sem o menor prejuizo das funcções principaes de ensino e pesquisa que á mesma competem.

Tendo ficado, por disposição do Regimento Interno, a seu cargo a organisação de cadernetas de identidade dos alumnos, pessoal docente e administrativo, foram identificados no anno expirante 87 pessoas, sendo 68 alumnos e 19 membros dos corpos docente e administrativo, aos quaes se expediram as competentes carteiras de identidade. Estas, devo aos bons officios de V. Ex. ${ }^{a}$ junto á Policia do Estado, foram todas registadas préviamente na Delegacia de Technica Policial, de sorte a terem o mesmo valor das carteiras officiaes. Cabeme, pois, frisando este facto, agradecer a confiança depositada pela nossa laboriosa Policia ao serviço de identificação da minha cadeira e pedir a V. Ex. ${ }^{a}$ que obtenha a renovação desta concessão ou, mesmo, a sua adopção definitiva.

Não ha necessidade de encarecer que, com a pratica dessa identificação dos estudantes e demais pessoas, ideada e realisada por Oscar Freire, ampliada, agora, com material mais abundante e idoneo que V Ex. ${ }^{a}$ me facultou, o curso pratico de medicina legal, na parte referente á dactyloscopia, poude ser feita com maior proveito para os alumnos.

Finalmente, a cadeira cooperou, tambem, pelo respectivo professor, em outros actos administrativos, como na Commissão de Inspectores, na Commissão do Regimento interno, na Commissão de elaboração da memoria historica, na Commissão de orientação do serviço da bibliotheca e na Commissão de Redacção dos "Annaes" sempre por honrosa determinação de $\mathrm{V}$ Ex. ${ }^{a}$. 
Desempenhando-me, assim, da ncumbencia regimental, eu quero felicitar a V. Ex. ${ }^{a}$ pelo brilho que tem sabido emprestar á sua gestão, tudo fazendo e tudo provendo, afim de que a Faculdade de Medicina de S. Paulo, de que me orgulho de ter sido discipulo e de que me honro hoje de ser professor, caminhe a largos passos para o explendido destino que lhe está reservado. Bem haja V. Ex. ${ }^{a}$ pela sua exclarecida acção e o D. Governo do Estado pela mão forte e prestigio que muito acertadamente tem dado a $\mathrm{V}$ Ex. $^{\mathrm{a}}$

Deus guarde a V. Ex. ${ }^{a}$ em sua obra meritoria Snr. director.

S. Paulo, 31 de dezembro de 1916.” 